\title{
High-throughput discovery of Hf promotion on the formation of hep Co and Fischer-Tropsch activity
}

\author{
Luis Alvarado Rupflin, ${ }^{a}$ Hendrik Van Rensburg, ${ }^{b}$ Marco Zanella, ${ }^{a}$ Elliot J. Carrington, ${ }^{\text {a }}$ Alexios \\ Grigoropoulos, ${ }^{a}$ Troy D. Manning, ${ }^{a}$ John B. Claridge, ${ }^{a}$ Alexandros P. Katsoulidis, ${ }^{\text {a }}$ Robert P. Tooze, ${ }^{b}$ \\ and Matthew J. Rosseinsky*,a
}

\author{
${ }^{a}$ Department of Chemistry, Materials Innovation Factory, University of Liverpool, Liverpool L7 3NY, U.K. \\ ${ }^{\mathrm{b}}$ Drochaid Research Services Ltd, Purdie Building, North Haugh, St Andrews, KY15 9ST
}

\begin{abstract}
A proxy-based high-throughput experimental approach was used to explore the stability and activity of Co-based Fischer Tropsch Synthesis catalysts with different promoters on various supports. The protocol is based on the estimation by XRD of active phase, Co, particle size and relative amounts of crystalline phases, Co to support. Sequential libraries samples enabled exploration of four Co loadings with five different promoters on six support materials. Catalysts stable to aging in syngas, displaying minimal change of particle size or relative area, were evaluated for their activity under industrial conditions. This procedure identified $\mathrm{SiC}$ as support for stable catalysts and a combination of $\mathrm{Ru}$ and $\mathrm{Hf}$ to promote the formation hcp Co. Unsupported bulk samples of Co with appropriate amounts of Ru and Hf revealed that the formation of hcp Co is independent of the support. The hcp Co containing catalyst presented the highest catalytic activity and $\mathrm{C}_{5+}$ selectivity amongst the samples tested in this study confirming the effectiveness of the proxy-based high-throughput method.
\end{abstract}

\section{Introduction}

The Fischer Tropsch Synthesis (FTS) is an important process for the production of long chain hydrocarbons from syngas (a mixture of $\mathrm{CO}$ and $\mathrm{H}_{2}$ ) using $\mathrm{Co}$ and $\mathrm{Fe}$ based catalyst materials. The development of active and stable catalysts for FTS is particularly difficult due to the complex nature of the reaction and the complex interactions between active material, support and promotors, the mixture of similar products and the long-time experiments needed for the measurement of activity and stability [1-3]. The activity of FTS catalysts is attributed to different factors such as the particle size, active metal phase, the metal surface area, and the interactions with the support material [4-7]. The presence of different Co polymorphs (fcc and hcp) for example plays an important role in the activity of the catalysts and has been subject to many studies recently, showing that the hcp Co phase is more active than the fcc Co phase in FTS [1, 2, 8-10]. The deactivation of the catalysts can occur through different mechanisms like sintering, oxidation, formation of metal-support compounds, carbon deposition and poisoning $[4,7,11,12]$. Realistic investigations addressing the activity and stability of FTS catalysts require extended testing times and diverse catalyst sets to delineate the effect of the different factors.

The formation and stabilization of the hcp Co phase for FTS catalysts has been thoroughly investigated $[1,2,8-10,13,14]$. The hcp Co phase is destabilized with increasing temperature because of its higher 
surface energy compared to fcc $\mathrm{Co}$ [15]. Thus, above a temperature of approx. $400{ }^{\circ} \mathrm{C}$ fcc $\mathrm{Co}$ is the main phase observed [16]. de la Pena et al. [17] reported the formation of Co hcp particles by reducing $\mathrm{Co}_{3} \mathrm{O}_{4}$ nanoparticles in a $\mathrm{H}_{2}$ and $\mathrm{CO}$ gas mixture. The authors observed the formation of a graphitic layer encapsulating the hcp Co particles, which stabilizes the hcp phase by decreasing the surface energy and inhibits the phase change. Under these conditions the hcp Co phase remains stable up to a temperature of $700{ }^{\circ} \mathrm{C}$. To achieve the formation of the hep phase on a support material, Gnanamani et al. [2] treat supported Co samples under $\mathrm{CO}$ flow and moderate temperatures $\left(230^{\circ} \mathrm{C}\right)$ to form the Co carbide $\left(\mathrm{Co}_{2} \mathrm{C}\right)$. The reduction of the $\mathrm{Co}_{2} \mathrm{C}$ at $230^{\circ} \mathrm{C}$ under $\mathrm{H}_{2}$ leads to the formation of the hep Co phase. The enhancement of the formation of the hcp Co from $\mathrm{Co}_{2} \mathrm{C}$ is attributed to structural similarity between these phases as both crystallize in the hexagonal system. Unfortunately, the samples were not reduced at temperatures higher than $230{ }^{\circ} \mathrm{C}$ to observe if the Co hop phase remains stable. No investigation has, to our knowledge, facilitated the formation of the Co hep phase by adding promotors and reducing the samples under $\mathrm{H}_{2}$ at temperatures as high as $500^{\circ} \mathrm{C}$.

High throughput (HT) experimentation is used to accelerate the screening of large catalyst sets, it has been successfully applied in the development of heterogeneous catalysts [18-20], and can be applied for the identification of stable FTS catalysts, by parallelizing the preparation, ageing and characterization of the samples. While testing the catalytic properties of the materials demands access to expensive and specialised equipment [21], the use of a proxy can accelerate the identification of suitable, stable and active materials without having to test all of them. In a previous paper [5] we reported the development of a proxy based method for the accelerated discovery of stable FTS catalysts. The workflow (Figure S1) developed includes the parallelized preparation, reduction, characterization of the samples augmented by an aging procedure under FTS similar conditions $\left(\mathrm{H}_{2}: \mathrm{CO}=3 ; 230{ }^{\circ} \mathrm{C}, 1\right.$ bar $)$ for $100 \mathrm{~h}$. The core of the proxy is the assessment of the stability and activity of the samples by estimating the change in particle size and the amount of metallic Co with the aging procedure. This is carried out by comparing the Co peak width and area (calculated relative to the support peak area). The last step is to run rapid high throughput TGA on selected samples to estimate the degree of reduction. The use of this method identified the composition of a series of highly stable, high surface area supported Co catalysts promoted by $\mathrm{Mg}$ and $\mathrm{Ru}$, and the optimization of the preparation protocol (i.e. order of addition, calcination steps).

The proxy described above is applied herein to investigate the effect of different support materials and promotors on the stability of Co based catalysts. The iterative workflow was used to first screen six different support materials (active carbon, $\mathrm{Al}_{2} \mathrm{O}_{3}, \mathrm{SiC}, \mathrm{SiO}_{2}, \mathrm{TiO}_{2}, \mathrm{ZrO}_{2}$ ) and five promotors ( $\mathrm{Ru}, \mathrm{Re}$, $\mathrm{Mo}, \mathrm{Mn}, \mathrm{La}$ ). This set of experiments identified $\mathrm{SiC}$ as a suitable support material and the screening of further promotors ( $\mathrm{Ru}, \mathrm{La}, \mathrm{Ce}, \mathrm{Pr}, \mathrm{Nd}, \mathrm{Hf})$ lead to the identification of the positive effects of a combination of $\mathrm{Co}, \mathrm{Ru}, \mathrm{Hf}$ on $\mathrm{SiC}$, which shows the formation of hep Co phase under our standard reduction conditions. Catalytic experiments under real FTS conditions revealed higher $\mathrm{C}_{5+}$ selectivity for a catalyst promoted with Ru and Hf. A more comprehensive study of the effects of Ru and Hf on the formation and stabilization of the hcp Co phase without support materials, shows that Ru and Hf alone stabilize this phase, but the effect increases significantly, when both are present, stabilizing the hcp Co phase to a temperature up to $500{ }^{\circ} \mathrm{C}$ and $12 \mathrm{~h}$.

\section{Experimental}

\section{Sample preparation}

Catalysts were synthesized by incipient wetness impregnation of the support materials. The support materials were weighed by a Quantos automated balance (Mettler Toledo XPE206) (250 mg) into 24 vials. An Eppendorf ep Motion 5075 was used for the liquid deposition onto the support materials; a 
plate holding an array of $4 \times 6$ vials containing the weighed support materials, allowed a variation of four different Co loadings and five different promotors on each support material (six support materials), this gives a total of 24 samples with different composition on each of the six support materials, i.e., a total of 144 samples.

The impregnation of the support materials is a multistep procedure. In a typical synthesis of a material with 20 wt.- $\%$ of $\mathrm{Co}, 0.212 \mathrm{ml}$ of a $4.0 \mathrm{M} \mathrm{Co}\left(\mathrm{NO}_{3}\right)_{2} \cdot 6 \mathrm{H}_{2} \mathrm{O}$ solution were added to the 24 vials each containing $250 \mathrm{mg}$ of SiC using the Eppendorf ep Motion 5075, followed by the addition of $0.047 \mathrm{ml}$ of water. After mixing the materials with a spatula, the vials are placed on a shaker for $1 \mathrm{~h}$ to obtain a homogenous distribution of the solution on the support material. The samples were dried at $100{ }^{\circ} \mathrm{C}$ for $16 \mathrm{~h}$. The impregnation of each promoter ( $\mathrm{Ru}, \mathrm{Re}, \mathrm{Mo}, \mathrm{Mn}, \mathrm{La}, \mathrm{Ce}, \mathrm{Pr}, \mathrm{Nd}$ and $\mathrm{Hf}$ ) is performed with the respective solution and water amounts, followed by a final drying step at $100{ }^{\circ} \mathrm{C}$ for $16 \mathrm{~h}$ and subsequent heat treatment at $300{ }^{\circ} \mathrm{C}$ under air for $6 \mathrm{~h}$ for the decomposition of the nitrates. The exact amount of promotor precursors and solutions used in each impregnation are provided in the Supporting Information file. The following step is the reduction of the samples under pure hydrogen flow (50 $\mathrm{ml} / \mathrm{min})$ at $500{ }^{\circ} \mathrm{C}$ for $12 \mathrm{~h}$ in ceramic well plates $(128 \times 43 \times 6 \mathrm{~mm}$, Figure S2). The ceramic well plate can hold 48 different samples and three of the plates can be reduced each time, making a total of 144 samples per run. Before taking the catalysts out of the furnace they are passivated with $1 \% \mathrm{O}_{2}$ in $\mathrm{N}_{2}$ $(100 \mathrm{ml} / \mathrm{min})$ at room temperature. The ceramic well plates are directly placed in a high throughput XRD (HT XRD, Panalytical X-pert Pro diffractometer with an XYZ stage) for the first characterization of the samples. The ceramic well plates are designed to fit on the XYZ stage.

The aging procedure of the samples was performed using the ceramic well plates under conditions approximating low temperature FTS with the flow of syngas $\left(\mathrm{H}_{2}: \mathrm{CO}=2: 1,90 \mathrm{ml} / \mathrm{min}\right)$ at $230{ }^{\circ} \mathrm{C}$ and ambient pressure for $100 \mathrm{~h}$. After the aging procedure the samples are passivated and transferred to the HT XRD for characterization.

Scale up of samples

Samples selected for scale up were prepared manually in an identical manner to the procedure described above. In a typical synthesis, a sample with $20 \mathrm{wt.}-\mathrm{\%}$ Co, $0.1 \mathrm{wt} .-\% \mathrm{Ru}$, and $5 \mathrm{wt} .-\%$ Hf supported on $\mathrm{SiC}$ (CoRuHf $\mathrm{SiC}$ ) was prepared as follows: $1.697 \mathrm{ml}$ of the $4.0 \mathrm{M} \mathrm{Co}\left(\mathrm{NO}_{3}\right)_{2} \cdot 6 \mathrm{H}_{2} \mathrm{O}$ solution was added to $0.463 \mathrm{ml}$ water and deposited on $2 \mathrm{~g}$ of $\mathrm{SiC}$ in a porcelain dish $(80 \mathrm{~mm}$ diameter) placed on a shaker. The sample was dried at $100{ }^{\circ} \mathrm{C}$ for $16 \mathrm{~h}$, prior to the next impregnation. The next impregnation with the $0.1 \mathrm{M} \mathrm{Ru}(\mathrm{NO})\left(\mathrm{NO}_{3}\right)_{3}$ solution is performed in an identical manner, but with the respective solution $(0.197 \mathrm{ml})$ and water $(2.083 \mathrm{ml})$ amounts, followed by a drying step at $100{ }^{\circ} \mathrm{C}$ for $16 \mathrm{~h}$. Finally, the impregnation with $0.47 \mathrm{M} \mathrm{HfCl}_{2} \mathrm{O}$ is performed with the respective solution $(1.192 \mathrm{ml})$ and water $(0.974$ $\mathrm{ml}$ ) amounts, followed by a last drying step at $100{ }^{\circ} \mathrm{C}$ for $16 \mathrm{~h}$ and a posterior heat treatment at $300{ }^{\circ} \mathrm{C}$ under air for $6 \mathrm{~h}$ for the decomposition of the nitrates. The second step is the reduction of the samples, which was performed in a tube furnace under pure hydrogen flow $(50 \mathrm{ml} / \mathrm{min})$ at $500{ }^{\circ} \mathrm{C}$ for $12 \mathrm{~h} \mathrm{in}$ ceramic boats $(80 \mathrm{~mm})$. Before taking the catalysts out of the furnace they are passivated at room temperature with $1 \% \mathrm{O}_{2}$ in $\mathrm{N}_{2}(100 \mathrm{ml} / \mathrm{min})$.

Unsupported samples

Unsupported samples were prepared by mixing quantities of the solutions to obtain the desired atomic ratios. In a typical synthesis of a sample with $\mathrm{Ru}: \mathrm{Co}=0.003$ and $\mathrm{Hf}: \mathrm{Co}=0.08$ atomic ratios $1.073 \mathrm{ml}$ of the $4 \mathrm{M} \mathrm{Co}\left(\mathrm{NO}_{3}\right)_{2} \cdot 6 \mathrm{H}_{2} \mathrm{O}$ solution, $0.127 \mathrm{ml}$ of the $0.1 \mathrm{M} \mathrm{Ru}(\mathrm{NO})\left(\mathrm{NO}_{3}\right)_{3}$ solution and $0.722 \mathrm{ml}$ of the $0.47 \mathrm{M} \mathrm{HFCl}_{2} \mathrm{O}$ solution were mixed together. After mixing the solutions, the drying, calcination and reduction steps are identical as for the supported samples described above. 


\section{Characterization}

High-throughput X-ray diffraction, XRD, was performed on a Panalytical X-pert Pro diffractometer with an XYZ stage using $\mathrm{Co} \mathrm{K} \alpha_{1} / \alpha_{2}($ ratio $=2)$ radiation between $38^{\circ}-55^{\circ} 2 \theta$, with a $0.039^{\circ}$ step size and $283 \mathrm{~s} /$ step. The particle size of the Co metal phase was calculated from the line broadening of the most intense fcc Co peak (111) using the Scherrer equation in X'Pert HighScore Plus software using a Si standard to determine the instrumental line width. Relative crystallinity was determined from the Co (111) to support XRD peak area ratio.

XRD of bulk samples was performed with a Panalytical X-pert Pro in Bragg-Brentano geometry laboratory X-ray diffractometer with $\mathrm{Co} \mathrm{K}_{\mathrm{a} 1}$ radiation $=1.78901 \AA$. Synchrotron XRD data was recorded on beamline I1 $1(\lambda=0.825972 \AA)$ at Diamond Light Source, UK.

Temperature programmed reduction (TPR) was measured using a Quantachrome ChemBET 3000 unit with a TPD; ca. $50 \mathrm{mg}$ of the calcined sample were loaded into a quartz cell and heated up to $100{ }^{\circ} \mathrm{C}$ for $30 \mathrm{~min}$ under $\mathrm{He}(100 \mathrm{ml} / \mathrm{min})$ to remove moisture and other adsorbed species from the samples. After cooling down to room temperature the sample was heated to $750{ }^{\circ} \mathrm{C}$ at $5{ }^{\circ} \mathrm{C} \mathrm{min}-1$ under a flow of $5 \%$ $\mathrm{H}_{2}$ in $\mathrm{N}_{2}\left(100 \mathrm{~cm}^{3} \mathrm{~min}^{-1}\right)$ to perform the analysis.

Fischer -Tropsch Synthesis

The activity tests in the FTS were performed at Drochaid Research Services Ltd in St. Andrews. The high throughput catalyst testing was done using a custom-built 32-tube fixed bed reactor test plant, designed by Integrated Lab Solutions and built by Premex. One unit, consisting of two heating blocks with eight reactors each, was used for the tests. The reactors $(\mathrm{L}=300 \mathrm{~mm} ; \mathrm{ID}=2.4 \mathrm{~mm}$; OD $=6.5 \mathrm{~mm})$ were accommodated in a heating furnace with an isothermal zone of $100 \mathrm{~mm}$. The catalyst bed length is of $7 \mathrm{~cm}$ with in the isothermal zone. $\mathrm{SiC}$ was used as an inert diluent material. The flow of the gases $\mathrm{CO}$ (CP grade, $\mathrm{BOC}), \mathrm{H}_{2}$ (CP grade, $\left.\mathrm{BOC}\right)$ and $\mathrm{Ar}$ (CP grade, $\left.\mathrm{BOC}\right)$ as an internal standard was controlled by mass flow controller and the pressure by a digital back pressure regulator. The concentration of reaction educts and products was measured using online GC techniques (Agilent Refinery Gas Analyser with a FID channel for the quantification of light hydrocarbons (DB-1 column $(2 \mathrm{~m} \times 0.32 \mathrm{~mm} \times 5 \mu \mathrm{m})$ and HP-AL/S column $(25 \mathrm{~m} \times 0.32 \mathrm{~mm} \times 8 \mu \mathrm{m}))$ and two TCD channels; TCD1 for the permanent gases $\mathrm{CH}_{4}, \mathrm{CO}_{2}, \mathrm{Ar}, \mathrm{N}_{2}$, and $\mathrm{CO}$ (HayeSep Q column (6 ft., 80/100 mesh) and a Mol Sieve 5A column (6 ft., 60/80 mesh)) and TCD2 for $\mathrm{H}_{2}$ (HayeSep $3 \mathrm{ft} ., 80 / 100$ mesh and Molsieve $8 \mathrm{ft}$., 60/80 mesh).

\section{Results and Discussion}

\section{Results of the first library}

The HT exploration of FTS catalysts is based on the prior assessment of stability of the active phase, metallic Co, on treatment with syngas as proxy for their activity. The applied workflow involves the parallel synthesis, syngas treatment and XRD characterisation of sample libraries. These are prepared by automated incipient wetness impregnation and reduced concurrently by $\mathrm{H}_{2}$ at $500{ }^{\circ} \mathrm{C}$. HT-XRD analysis is employed to determine the phase of $\mathrm{Co}$ and its particle size before and after the aging of samples under a syngas mixture, $\mathrm{H}_{2}: \mathrm{CO}=2: 1$, at $230^{\circ} \mathrm{C}$ for $100 \mathrm{~h}$. Large changes in the particle size of Co or in its overall crystallinity, estimated by the peak area ratio of Co to support, are taken as indicators of the lack of stability and predictors of low activity catalyst in FTS. 
The effects of the support material, the Co loading and the addition of promotors were investigated in the first library, which consisted of 144 samples. Support materials $\mathrm{Al}_{2} \mathrm{O}_{3}[1,11,22-30], \mathrm{TiO}_{2}[6,11$, 28, 31-37] $\mathrm{ZrO}_{2}[28,32,33], \mathrm{SiO}_{2}[2,11,28,32,38-45]$ active carbon (AC) [27, 30, 46, 47], and $\mathrm{SiC}$ $[48,49]$ were used. Despite the reactivity of metal oxides, particularly $\mathrm{Al}_{2} \mathrm{O}_{3}$, with Co they were selected as supports for their porosity and thermal stability. Non-oxide supports do not interfere with Co, which can be reduced at relatively low temperatures. $\mathrm{Ru}, \mathrm{Re}, \mathrm{Mo}, \mathrm{Mn}$ and La were used as promotors. $\mathrm{Ru}$ and Re known to increase the reducibility of cobalt on support materials $[6,11,25,26,28,31,33]$ and increase the resistance to deactivation. Furthermore Ru is known to be the most active element in FTS. The transition metals Mo and Mn were selected too, since they have been reported to increase the chaingrowth probability factor to larger hydrocarbons in the product stream [30, 35, 40, 44, 45, 50, 51] and finally the rare earth metal $\mathrm{La}$, which has been reported to increase the dispersion of Co on the support $[28,29,37,42,44,46,52]$.

Table 1 Overview of the of the first library with 144 different compositions (support x Co loading x promoter): six different support materials with four different Co loadings each and six different promotors (none, Ru and Re with low loading levels (0.1 wt.-\%) and Mo, Mn and La with high loading levels (5.0 wt.-\%))

\begin{tabular}{|ccc|}
\hline Support & Co loading (\%) & Promoter \\
\hline $\mathrm{Al}_{2} \mathrm{O}_{3}$ & 5 & - \\
$\mathrm{SiO}_{2}$ & 10 & $\mathrm{Ru}(0.1 \%)$ \\
$\mathrm{TiO}_{2}$ & 15 & $\mathrm{Re}(0.1 \%)$ \\
$\mathrm{ZrO}_{2}$ & 20 & $\mathrm{Mo}(5 \%)$ \\
$\mathrm{SiC}$ & $\mathrm{Mn}(5 \%)$ \\
$\mathrm{AC}$ & & $\mathrm{La}(5 \%)$ \\
\hline
\end{tabular}

Based on a first assessment of the HT XRD patterns, samples showing no metallic Co peaks after the reduction or after the aging procedure were immediately ruled out. This is the case for the samples supported on $\mathrm{ZrO}_{2}$ and samples with only 5 wt.-\% Co loading on every other support. The results of crystallite size analysis for aged samples are plotted versus the crystallite size before aging (Fig. 1a). The $\mathrm{y}=\mathrm{x}$ line is used to display the increase, points above the line, or the decrease, points below the line, of the crystallite size after the syngas aging process. Samples prepared on $\mathrm{SiO}_{2}, \mathrm{AC}$ and $\mathrm{TiO}_{2}$ show an increase in the crystallite size after aging, up to a doubling of the particle size after the aging procedure observed for $\mathrm{SiO}_{2}, \mathrm{AC}$ and $\mathrm{TiO}_{2}$, while the samples supported on $\mathrm{SiC}$ show an increase to a lesser extent, from 27 to $36 \mathrm{~nm}$. For samples supported on $\mathrm{Al}_{2} \mathrm{O}_{3}$ a decrease of the particle size from 33 to $16 \mathrm{~nm}$, in the most extreme case, was observed. Figure $1 \mathrm{~b}$ shows the peak area ratio between Co and support, for the three crystalline supports $\left(\mathrm{Al}_{2} \mathrm{O}_{3}, \mathrm{TiO}_{2}\right.$ and $\left.\mathrm{SiC}\right)$, before and after the aging procedure. $\mathrm{TiO}_{2}$ and $\mathrm{Al}_{2} \mathrm{O}_{3}$ show a decrease of the peak area ratio after the aging procedure (up to $70 \%$ Co peak area ratio loss on samples supported on $\mathrm{TiO}_{2}$ and up to $60 \%$ Co peak area ratio loss on samples supported on $\mathrm{Al}_{2} \mathrm{O}_{3}$ ), while the area ratio of samples on $\mathrm{SiC}$ show the smallest change (between 8 and $23 \%$ Co peak area ratio increase). The effect of the different promotors can clearly be observed for the samples supported on $\mathrm{SiC}$ (Figure 1c and d). The samples that show the smallest change in the Co peak area ratio, are those promoted with $\mathrm{Ru}$ (from 0.63 to 0.75 ), $\mathrm{La}$ (from 0.65 to 0.83 ) and Mo (from 0.70 to 0.77).

Since samples prepared on $\mathrm{SiC}$ show the smallest change of Co crystallite size and peak area ratio after the aging procedure, they were identified as hits from the first library. The samples with a Co loading of 15 wt.- $\%$; promoted with Ru and Re, at 0.1 wt.-\% loading, and Mn, Mo or La, 5 wt.-\% loading were scaled up and tested in FTS under industrial conditions. These samples were named after the active component and the promoter, i.e. the sample CoRu had $15 \mathrm{wt} .-\%$ Co and $0.1 \mathrm{wt} .-\% \mathrm{Ru}$. The cobalt time yield of each sample on FTS at 20 bar and three different temperatures is shown on Figure 2. At all three 
temperatures the sample CoRuLa showed the highest activity, CoMn showed the lowest and the other five samples $\mathrm{Co}, \mathrm{CoRu}, \mathrm{CoRe}, \mathrm{CoLa}$ and $\mathrm{CoMo}$ showed similarly intermediate activity. Apart from the highest activity the sample CoRuLa also exhibited the highest selectivity for liquid products, $\mathrm{C}_{5+}$ $80.75 \%$, and very low selectivity towards $\mathrm{CO}_{2}$ (Table 2). Promotors $\mathrm{Ru}$ and Re did not enhance the selectivity of $\mathrm{C}_{5+}$ compared to Co sample while CoMn, CoMo and CoLa provided significantly lower $\mathrm{C}_{5+}$ selectivities.

The positive effect of the simultaneous promotion of $\mathrm{Ru}$ and $\mathrm{La}$ on the activity of the catalyst prompted the further investigation of similar systems, in this case expanding the investigation of the promotion with other rare earth metals, which will be discussed in the next section.

(a)

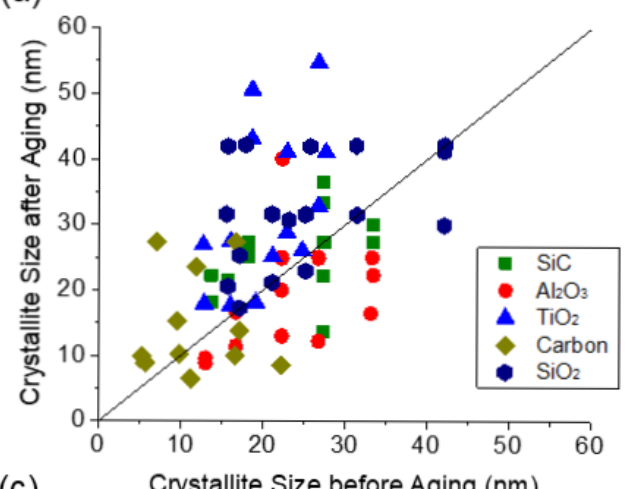

(c)

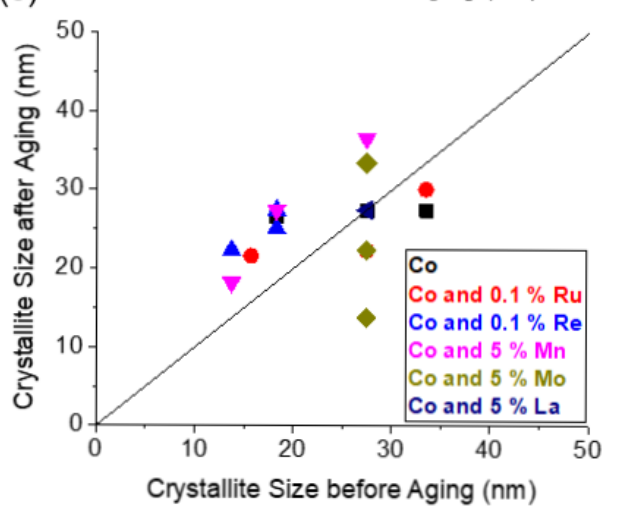

(b)

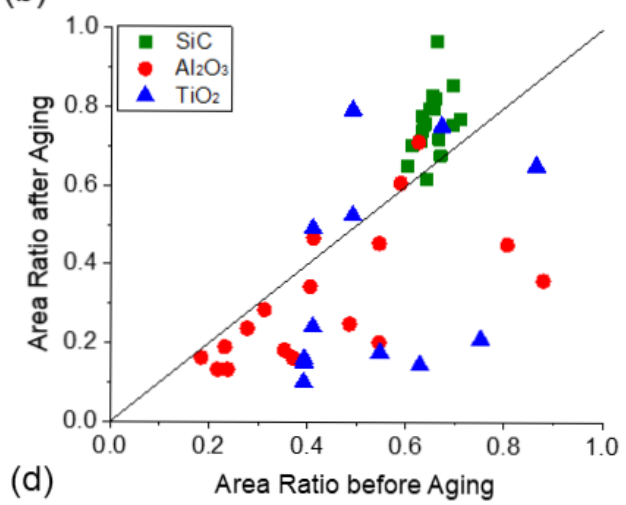

(d)

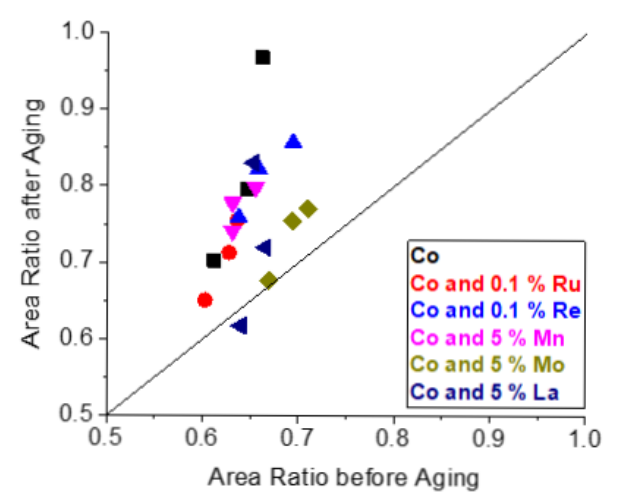

Figure 1 HT screening of the first library. (a) The effect of the support material on the changes of Co crystallite size and (b) peak area ratio with syngas aging. (c) The effect of promoter on the changes of Co crystallite size and (d) peak area ratio of $\mathrm{SiC}$ supported samples with syngas aging. 


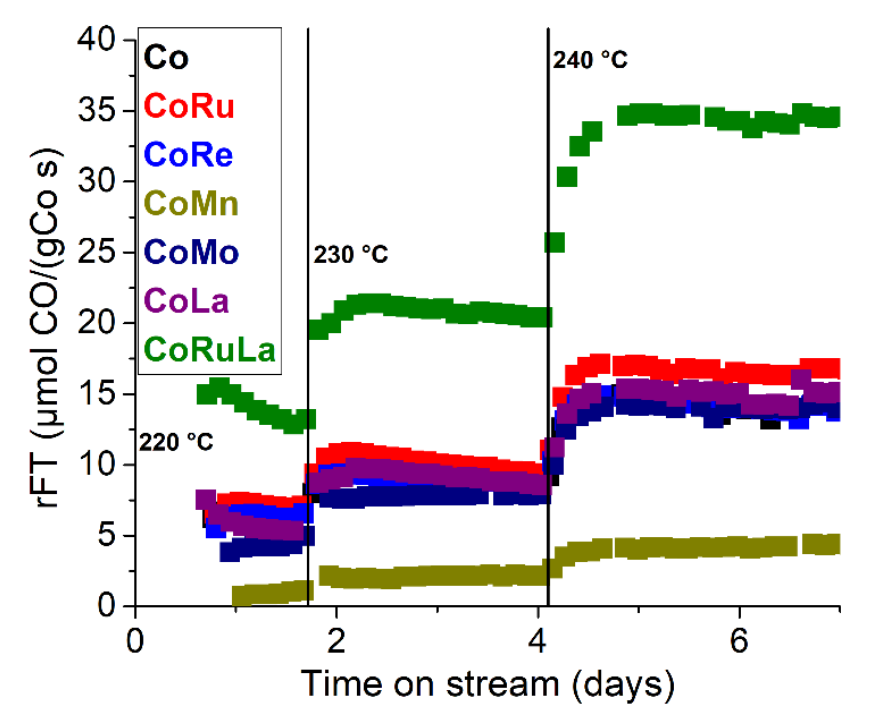

Figure 2 The cobalt time yield on FTS of seven catalysts with different promotors at three different temperatures.

Table 2. FTS rate and gas phase product distribution at $230{ }^{\circ} \mathrm{C}$ of the catalysts with different promotors.

\begin{tabular}{|c|c|c|c|c|c|c|c|}
\hline \multicolumn{2}{|c|}{ Sample } & \multirow{2}{*}{$\begin{array}{c}\text { Temperature } \\
{ }^{\circ} \mathrm{C}\end{array}$} & \multicolumn{4}{|c|}{ Selectivity } & \multirow{2}{*}{$\begin{array}{c}\text { FTS Rate } \\
{[\mu \mathrm{mol} \mathrm{CO} /(\mathrm{gCo} s)]}\end{array}$} \\
\hline Composition & Support & & $\begin{array}{c}\mathrm{CH}_{4} \\
\% \\
\end{array}$ & $\begin{array}{c}\mathrm{C}_{2-4} \\
\%\end{array}$ & $\begin{array}{l}\mathrm{C}_{5+} \\
\%\end{array}$ & $\begin{array}{c}\mathrm{CO}_{2} \\
\% \\
\end{array}$ & \\
\hline $\mathrm{Co}$ & $\mathrm{SiC}$ & 230 & 11.22 & 10.93 & 76.46 & 1.39 & 9.06 \\
\hline $\mathrm{CoRu}$ & $\mathrm{SiC}$ & 230 & 9.33 & 9.83 & 78.55 & 2.28 & 10.07 \\
\hline $\mathrm{CoRe}$ & $\mathrm{SiC}$ & 230 & 10.85 & 11.74 & 76.10 & 1.31 & 9.02 \\
\hline CoMn & $\mathrm{SiC}$ & 230 & 26.17 & 29.64 & 44.19 & 0.00 & 2.17 \\
\hline CoMo & $\mathrm{SiC}$ & 230 & 15.99 & 13.59 & 65.90 & 4.52 & 7.86 \\
\hline $\mathrm{CoLa}$ & $\mathrm{SiC}$ & 230 & 10.55 & 16.23 & 72.60 & 0.62 & 9.25 \\
\hline CoRuLa & $\mathrm{SiC}$ & 230 & 8.74 & 10.06 & 80.75 & 0.44 & 20.69 \\
\hline
\end{tabular}

\section{Results of the second library}

A second library focussed on the effect of the content of $\mathrm{Ru}$ and the inclusion of rare earth elements (La, $\mathrm{Ce}, \mathrm{Pr}, \mathrm{Nd}$ ), and $\mathrm{Hf}$ as promotors for Co-based materials supported on SiC. The proxy screening on the first library proved the suitability of $\mathrm{SiC}$ as a support material and the positive effect of $\mathrm{Ru}$ and $\mathrm{La}$ on the stability of Co after the aging procedure. Furthermore, the first catalytic test showed the positive effects of the simultaneous promotion of $\mathrm{La}$ and $\mathrm{Ru}$ enhancing the $\mathrm{CO}$ conversion rate and the $\mathrm{C}_{5+}$ selectivity.

While the effect of rare earths on Co-based catalysts has been thoroughly investigated [44, 45, 52, 53], little is known about the effect of the promotion of Hf [34] and its effect on the phase formation and stabilization of Co particles. Hf was chosen, because it is in the same group as Ti and $\mathrm{Zr}$, whose oxides are known promotors and support materials for FT catalysts and because it is in the same period as the rare earth metals. Many patents mention the use of Hf as a promoter for Co based FTS catalysts, but only one patent [34] could be found, where experimental data showing the positive effect of $\mathrm{Hf}$ promotion of Co based catalysts is presented. 
The effect of rare earths ( $\mathrm{La}, \mathrm{Ce}, \mathrm{Pr}, \mathrm{Nd}$ ) or $\mathrm{Hf}$ addition at different loading levels was investigated for samples loaded with $\mathrm{Co}$ and $\mathrm{Co}$ and $\mathrm{Ru}$, as shown in Table 3. The results obtained after submitting the samples to the workflow described above can be seen in Figure 3, where peak area ratio of Co after the aging procedure is plotted over the peak area ratio before the aging procedure. Each colour represents a different promoter, the shape of the symbols represents different levels of each promoter and the open symbols represent samples without Ru. Samples with Ru and 2.5 or 5 wt.\% Hf, along with samples promoted with $\mathrm{Ru}$ and $\mathrm{Ce}$ and samples with $\mathrm{Ru}$ and $\mathrm{Pr}$, show a good stability under aging conditions. Samples promoted without $\mathrm{Ru}$ prove to be stable under the aging conditions but show lower Co peak area ratios than samples promoted with $\mathrm{Ru}$. The samples promoted with $\mathrm{Ru}$ and $\mathrm{Hf}$ are particularly striking, whilst the sample with $5 \mathrm{wt} . \% \mathrm{Hf}$ and $0.1 \mathrm{wt} . \% \mathrm{Ru}$ stabilizes the Co peak area as shown in Figure 3, it also shows a further peak on the XRD patterns, which corresponds to the hcp Co phase (Figure S3 SI). The formation of the hcp phase can only be observed for samples promoted with Hf and $\mathrm{Ru}$.

Table 3 Overview of the 30 different compositions of the second library prepared on SiC, combining the promotion of Co catalyst with Ru and rare earths or Hf.

\begin{tabular}{|c|c|cccc|cccc|}
\hline \multicolumn{2}{|c|}{$\begin{array}{c}\text { Co and Ru } \\
(\mathrm{wt} \%)\end{array}$} & \multicolumn{7}{|c|}{ Promoter $(\mathrm{wt} \%)$} \\
\cline { 2 - 10 } & - & - & 5 & 10 & - & - & 2.5 & 5 & - \\
\hline 20 & - & 2.5 & 5 & 10 & 15 & 1.25 & 2.5 & 5 & 10 \\
\hline 20 & 0.1 & &
\end{tabular}

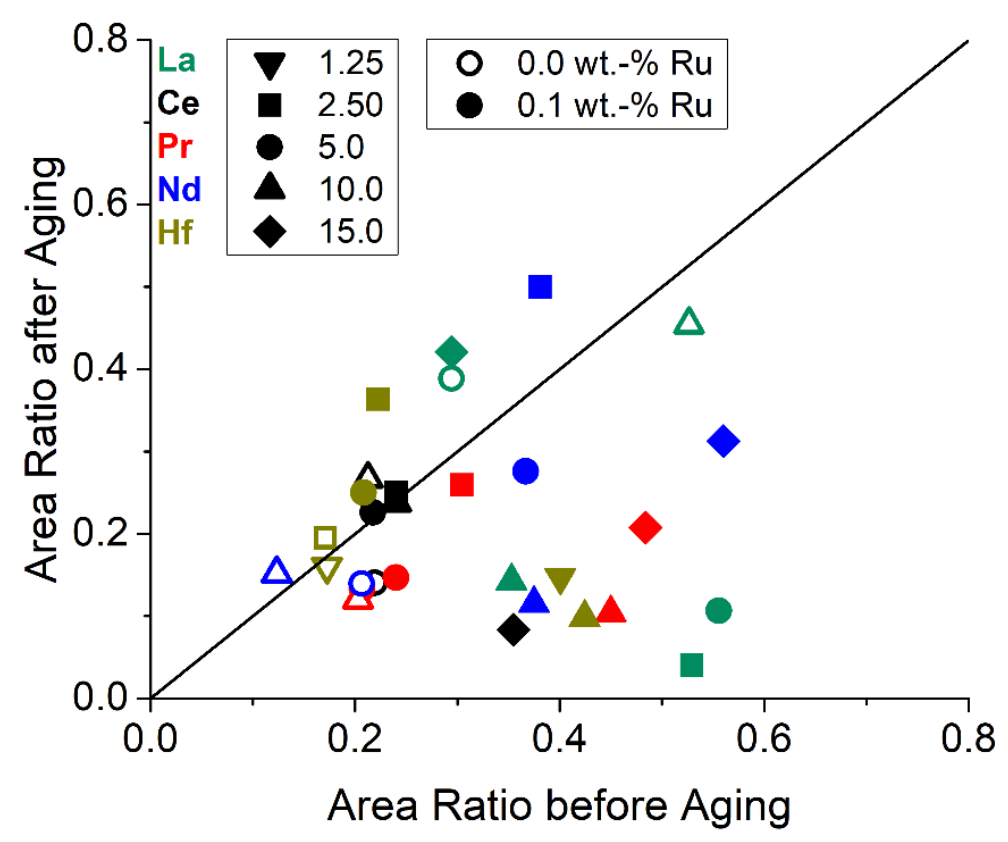

Figure 3 Results of the proxy evaluation of the effect of the addition of $\mathrm{La}, \mathrm{Ce}, \mathrm{Pr}, \mathrm{Nd}, \mathrm{Hf}$ and $\mathrm{Ru}$ to Co based samples supported on $\mathrm{SiC}$

\section{Scale up of samples}

The samples with $5 \mathrm{wt} . \%$ loading of promotors displayed the highest stability in the proxy screening of the second library and they were selected for scale up, characterisation and FTS testing. All samples have fixed loadings of Co (20 wt.\%), Ru, (0.1 wt.\%), and either Ce, Pr, La or Hf (5 wt.\%) or no promoter. 
A sixth sample with standard Co loading (20 wt.\%) alone supported on $\mathrm{SiC}$ was made for comparison purposes. The samples are named according to the active component and the promotors in a similar fashion to the first set of samples.

The XRD patterns of the six scaled up samples and of the pure SiC obtained from the synchrotron source at Beamline I1 1 of Diamond Light Source are presented in Figure 4. The catalysts show the formation of the fcc Co phase, displaying peaks at d-spacing of 2.04 and $1.77 \AA$ (the (111) and (200) lattice planes respectively). The sample promoted with Hf displays further peaks at d-spacing of 1.91 and $1.15 \AA$ that correspond to the hep phase of Co (the (101) and (110) planes respectively). The catalysts promoted with $\mathrm{Ru}, \mathrm{Ce}$ and $\mathrm{Ru}$, and $\operatorname{Pr}$ and $\mathrm{Ru}$ also show small and broad peaks at a d-spacing of 1.91 but with a very low intensity. A strong enhancement of the formation of the hep Co phase can only be observed in the sample promoted with $\mathrm{Hf}$ and $\mathrm{Ru}$.

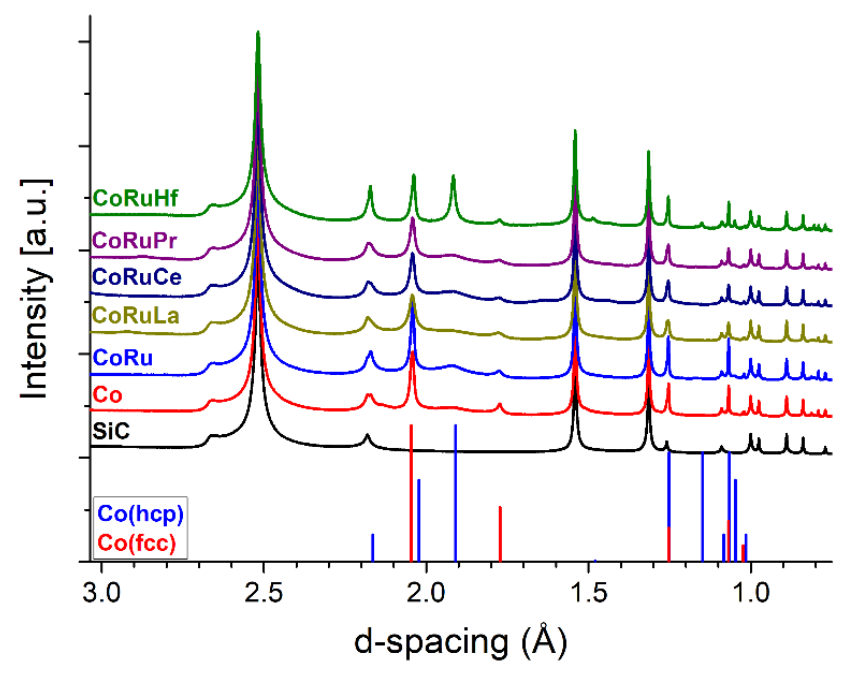

Figure 4 Synchrotron PXRD patterns of the six scaled up samples selected from the second library and of the pure $\mathrm{SiC}$.

\section{Temperature programmed reduction}

In order to understand the effect of each promoter on the reduction behaviour of $\mathrm{Co}$, the samples were submitted to a TPR analysis under $5 \% \mathrm{H}_{2}$ in $\mathrm{N}_{2}$ (Figure 5). The sample containing only $20 \mathrm{wt.-} \% \mathrm{Co}$ shows two different peaks, the first at a lower temperature $\left(300-375^{\circ} \mathrm{C}\right)$ is associated with the reduction of the $\mathrm{Co}$ (III) species to $\mathrm{Co}$ (II), and the second one, at a higher temperature $\left(400-500{ }^{\circ} \mathrm{C}\right)$ with the reduction of the $\mathrm{Co}(\mathrm{II})$ species to $\mathrm{Co}(0)$ [28]. The addition of Ru to the samples enhances the reducibility of the samples lowering the temperature of both reduction steps. The addition of both $\mathrm{Ru}$ and rare earth metals as promotors leads to an increase of the reduction temperature for both steps, compared to those promoted by $\mathrm{Ru}$ alone, as illustrated by the TPR for the samples promoted with $\mathrm{Ru}$ and $\mathrm{La}$ or Pr. The sample promoted with mixture of $\mathrm{Ru}$ and Ce shows similar reduction behaviour in relation to the sample promoted only with Ru. Again it is the sample promoted with $\mathrm{Ru}$ and Hf which shows the most differentiated reduction behaviour. The reduction temperature of the Co(III) species is raised to ca. 350 ${ }^{\circ} \mathrm{C}$, simultaneously the reduction temperature for the $\mathrm{Co}$ (II) species is reduced to ca. $400-450{ }^{\circ} \mathrm{C}$. The peaks for both steps merge together in a single reduction peak between $325-450{ }^{\circ} \mathrm{C}$, where they cannot be differentiated from each other. 


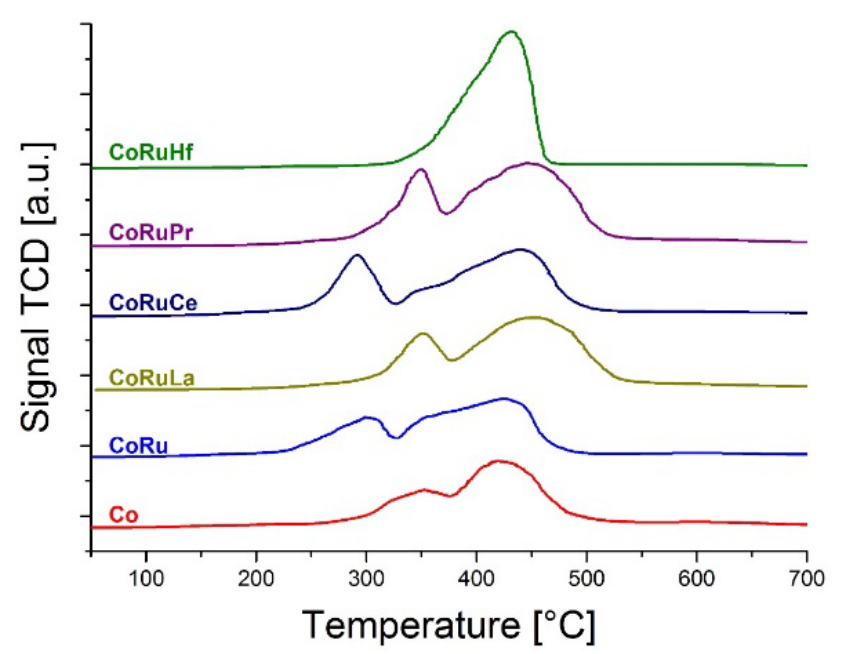

Figure $5 \mathrm{H}_{2}$-TPR profile of the scaled-up samples. The addition of $\mathrm{Hf}$ to the samples leads to a merge of the reduction peaks of Co oxides.

\section{Fischer-Tropsch Synthesis}

The scaled-up materials were tested under industrial FTS conditions in a parallel reactor system at 20 bar and three different temperatures (Figure 6a). At $210^{\circ} \mathrm{C}$ the materials CoRu, CoRuLa, CoRuCe and CoRuPr show similar Co time yield and only the material CoRuHf shows higher performance. At 220 ${ }^{\circ} \mathrm{C}$ all the materials display an increase in their activity with CoRuHf being the most active and CoRuPr showing higher yield than the rest of the samples. At $230{ }^{\circ} \mathrm{C}$ all the materials show different $\mathrm{CO}$ conversion rates in the FTS with the following activity order CoRuHf $>\mathrm{CoRuPr}>\mathrm{CoRuLa}>\mathrm{CoRuCe}>$ $\mathrm{CoRu}$. The material promoted with $\mathrm{Ru}$ and $\mathrm{Hf}$ not only shows the highest yield at all temperatures, it also displays the highest selectivity values towards $\mathrm{C}_{5^{+}}$components as Table 4 shows. The material CoRuHf achieves $\mathrm{C}_{5+}$ selectivity values up to $80.19 \%$ with a $\mathrm{CO}$ conversion rate of up to 23.90 $\mu \mathrm{molCO} /(\mathrm{gCo} \cdot \mathrm{s})$, followed by the $\mathrm{CoRuCe}$ material $\left(77.33 \% \mathrm{C}_{5^{+}}\right.$selectivity and 20.22 $\mu \mathrm{molCO} /(\mathrm{gCo} \cdot \mathrm{s}))$, the CoRu material, which shows high selectivity towards $\mathrm{C}_{5+}$ components $(76.90 \%)$ but lower $\mathrm{CO}$ conversion rates $\left(14.43 \mu \mathrm{molCO} /(\mathrm{gCo} \cdot \mathrm{s})\right.$, and the $\mathrm{CoRuPr}$ material $\left(75.38 \% \mathrm{C}_{5+}\right.$ selectivity and $20.38 \mu \mathrm{molCO} /(\mathrm{gCo} \cdot \mathrm{s}))$. The material with the lowest $\mathrm{C}_{5+}$ selectivity is CoRuLa with $68.57 \%$ and $17.14 \mu \mathrm{molCO} /(\mathrm{gCo} \cdot \mathrm{s})$. Furthermore, the CoRuHf material also shows the lowest selectivity towards $\mathrm{CO}_{2}(0.36 \%)$ and $\mathrm{C}_{2}-\mathrm{C}_{4}$ components $(7.90 \%)$ at $230{ }^{\circ} \mathrm{C}$. Finally, the CoRuHf material shows a selectivity towards $\mathrm{CH}_{4}$ of $11.55 \%$ at $230{ }^{\circ} \mathrm{C}$, which is only lower than the selectivity achieved by the CoRuLa material $(11.84 \%)$. Methane, being a raw material for the production of syngas, and $\mathrm{CO}_{2}$, are undesired by-products in FTS [54].

A comparison between the fresh and used samples is shown on Figure 6b. Compared with the fresh catalysts the XRD characterization of the spent catalysts shows no significant loss of the fcc Co phase for any of the catalysts. The CoRuHf shows the presence of the hcp Co phase in the fresh and in the spent material. Both fcc and hcp Co phases are stable under the testing conditions, i.e., the deactivation observed at $230{ }^{\circ} \mathrm{C}$ during the catalytic test is not caused by the formation of Co oxides.

The higher yield and the higher $\mathrm{C}_{5+}$ selectivity values of the $\mathrm{Hf}$ containing material compared to the rest of the catalysts is consistent with the formation of the hcp Co phase. The effect of the formation of the different phases on the activity of the catalysts has been studied previously [1-3, 9, 10, 23, 41]. By treating the materials under different conditions, phase pure fcc and hcp Co catalysts were prepared on the support materials, as investigations by Lyu [10] and Gnamani [2] showed. The comparison between the activities of those materials demonstrated that catalysts with the hep phase achieved a higher activity 
than the other materials. DFT calculations indicate that hep Co has a higher activity for CO activation in the presence of $\mathrm{H}_{2}$ than fcc Co [9].
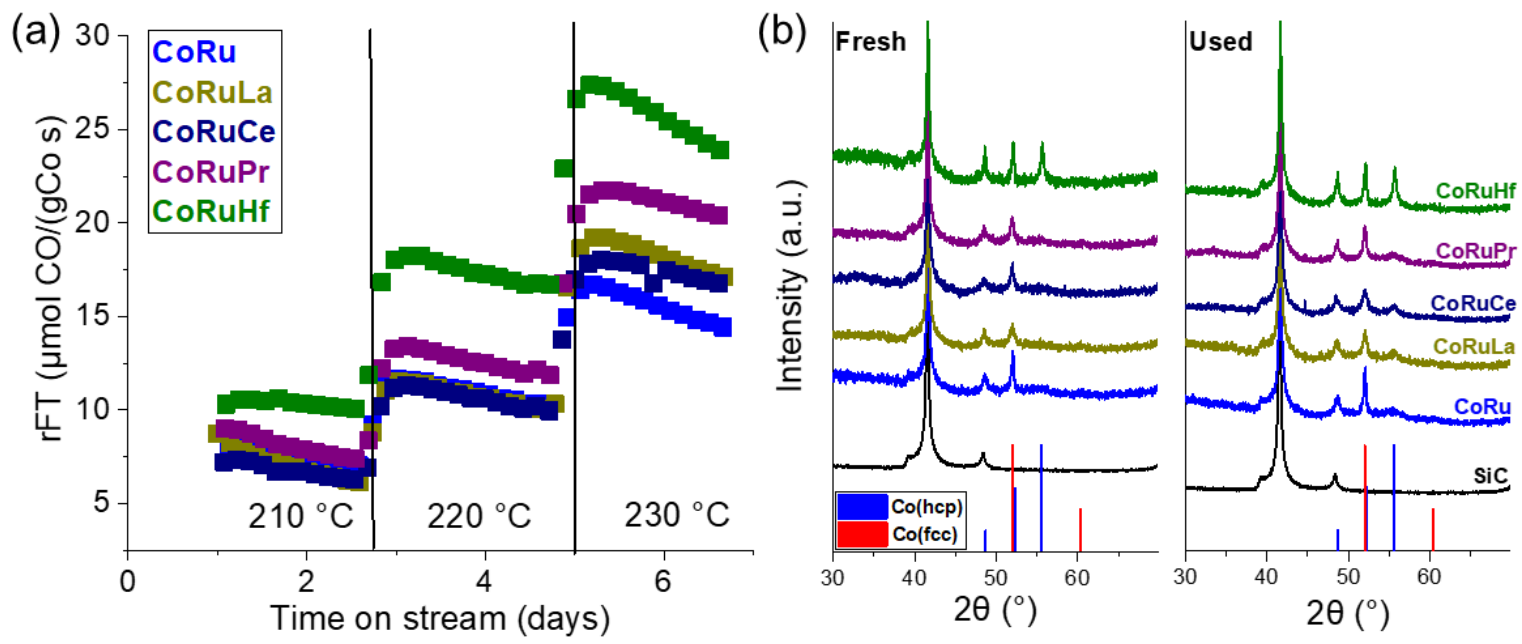

Figure 6 (a) Cobalt time yield on FTS from the catalysts selected from the second library. (b) Comparison of the fresh and spent catalyst materials.

Table 4 FTS rate and products' selectivity at $230^{\circ} \mathrm{C}$ of the catalysts selected from the second library.

\begin{tabular}{|c|c|c|c|c|c|c|c|}
\hline \multicolumn{2}{|c|}{ Sample } & \multirow{2}{*}{$\begin{array}{c}\text { Temperature } \\
{ }^{\circ} \mathrm{C} \\
\end{array}$} & \multicolumn{4}{|c|}{ Selectivity } & \multirow{2}{*}{$\begin{array}{c}\text { FTS Rate } \\
{[\mu \mathrm{mol} \mathrm{CO} /(\mathrm{gCos})]}\end{array}$} \\
\hline Composition & Support & & $\begin{array}{c}\mathrm{CH}_{4} \\
\%\end{array}$ & $\begin{array}{c}\mathrm{C}_{2-4} \\
\%\end{array}$ & $\begin{array}{l}\mathrm{C}_{5+} \\
\%\end{array}$ & $\begin{array}{c}\mathrm{CO}_{2} \\
\%\end{array}$ & \\
\hline $\mathrm{CoRu}$ & $\mathrm{SiC}$ & 230 & 11.48 & 10.80 & 76.90 & 0.82 & 14.43 \\
\hline CoRuLa & $\mathrm{SiC}$ & 230 & 11.84 & 18.99 & 68.57 & 0.60 & 17.14 \\
\hline CoRuCe & $\mathrm{SiC}$ & 230 & 9.48 & 12.64 & 77.33 & 0.55 & 20.22 \\
\hline CoRuPr & $\mathrm{SiC}$ & 230 & 10.14 & 14.00 & 75.38 & 0.48 & 20.38 \\
\hline CoRuHf & $\mathrm{SiC}$ & 230 & 11.55 & 7.90 & 80.19 & 0.36 & 23.90 \\
\hline
\end{tabular}

\section{Unsupported Samples}

The formation of the hep Co phase supported on $\mathrm{SiC}$ and promoted with $\mathrm{Hf}$ and $\mathrm{Ru}$ motivated us to further investigate the effect of $\mathrm{Hf}$ and $\mathrm{Ru}$ on formation of hcp Co. To eliminate the effect from the support material a set of samples with different Hf:Co and Ru:Co atomic ratios were prepared and reduced at different temperatures and for different times. Samples showing a reduction time of $0 \mathrm{~h}$ were held at the reduction temperature for $5 \mathrm{~min}$ before cooling down at a natural rate. The results from the XRD characterization (Fig. 7) show the patterns of samples with three different Hf:Co ratios reduced at different temperatures and for different times. The sample with $\mathrm{Hf}: \mathrm{Co}=0$ is reduced completely at 300 ${ }^{\circ} \mathrm{C}$ and shows the formation of the hcp Co phase. An increase in the reduction temperature leads to the formation of the fcc Co phase. The formation of the fcc phase can be observed by the increase of intensity of the $(111)$ peak $\left(2 \theta=52.01^{\circ}\right)$. At a reduction temperature of $500{ }^{\circ} \mathrm{C}$ almost all the hep Co has been converted to fcc phase. The $(200)$ peak $\left(2 \theta=60.34^{\circ}\right)$ of the fcc Co phase can be observed clearly while there is an associated significant decrease in intensity of the (100) and (101) peaks of the Co hcp phase. The phase composition of each sample has been obtained by Rietveld refinement (Figure S4). The decrease in the content of the hcp Co phase proceeds with longer reduction times, but even 
after $12 \mathrm{~h}$ at $500{ }^{\circ} \mathrm{C}$, the content of hcp Co phase is $45 \mathrm{wt} \%$. The addition of $\mathrm{Hf}$ to the sample impedes the reduction of the samples and the conversion of the hcp into the fcc Co phase, as the XRD patterns of the samples with Hf:Co $=0.04$ and Hf:Co $=0.08$ show. Samples with Hf:Co $=0.04$ reduced at 300 ${ }^{\circ} \mathrm{C}$ show mainly the peaks of $\mathrm{CoO}$ and some hcp Co. An increase in temperature to $350{ }^{\circ} \mathrm{C}$ leads to further formation of the hcp Co. At $400{ }^{\circ} \mathrm{C}$ only the mettalic Co phases can be observed, while increasing the temperature to $500^{\circ} \mathrm{C}$ and reduction times at $12 \mathrm{~h} \mathrm{hcp} \mathrm{Co} \mathrm{remains} \mathrm{the} \mathrm{dominant} \mathrm{phase,} 84 \mathrm{wt} \%$. The behaviour of the samples with $\mathrm{Hf}: \mathrm{Co}=0.04$ and $\mathrm{Hf}: \mathrm{Co}=0.08$ is very similar. At $300{ }^{\circ} \mathrm{C}$ only $\mathrm{CoO}$ is present in the sample, and at $400{ }^{\circ} \mathrm{C}$ the most of the $\mathrm{CoO}$ has been transformed to the metallic hcp Co phase. Reducing the sample at $500{ }^{\circ} \mathrm{C}$ for $12 \mathrm{~h}$ the most of Co is present as the hcp phase, $86 \mathrm{wt} \%$ while very broad peaks corresponding to monoclinic $\mathrm{HfO}_{2}$ have been appeared.

The addition of $\mathrm{Ru}$ to the sample promotes the formation of the hcp Co phase at low temperature as no oxide phase is detected in any of the samples (Figure 8a). The content of hcp phase is higher, at all reduction temperatures, when compared to the samples with no Ru (Figures S4 and S5). The stabilization of the hcp Co phase is enhanced when the samples are promoted with Ru and Hf as shown by the XRD patterns in Figure $8 \mathrm{~b}$ and $\mathrm{c}$. The samples with $\mathrm{Ru}: \mathrm{Co}=0.003$ and $\mathrm{Hf}: \mathrm{Co}=0.04$ or $\mathrm{Hf}: \mathrm{Co}=0.08$ indicate that even after $12 \mathrm{~h}$ reduction time at $500{ }^{\circ} \mathrm{C}$ the content fcc Co phase reaches only $6 \mathrm{wt} \%$ and $11 \mathrm{wt} \%$ respectively.

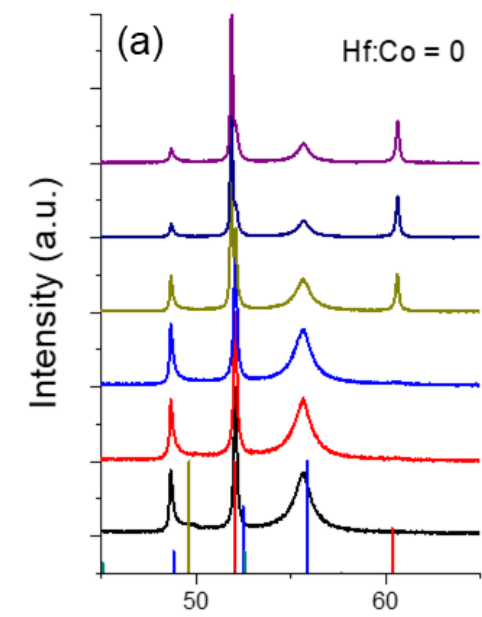

$2 \theta\left({ }^{\circ}\right)$

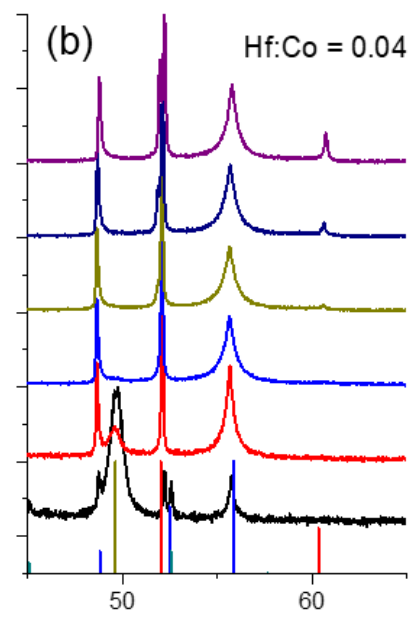

$2 \theta\left({ }^{\circ}\right)$

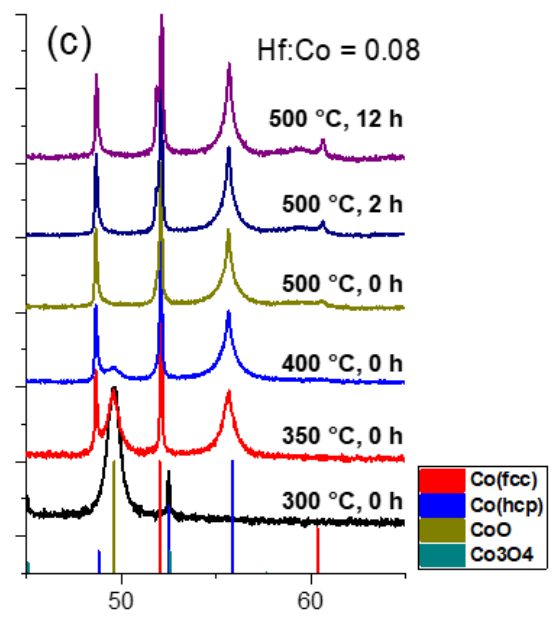

$2 \theta\left({ }^{\circ}\right)$

Figure 7 PXRD patterns of unsupported Co samples with (a) Hf:Co = 0, (b) Hf:Co =0.04 and (c) Hf:Co =0.08 and reduced at different temperatures and times. 

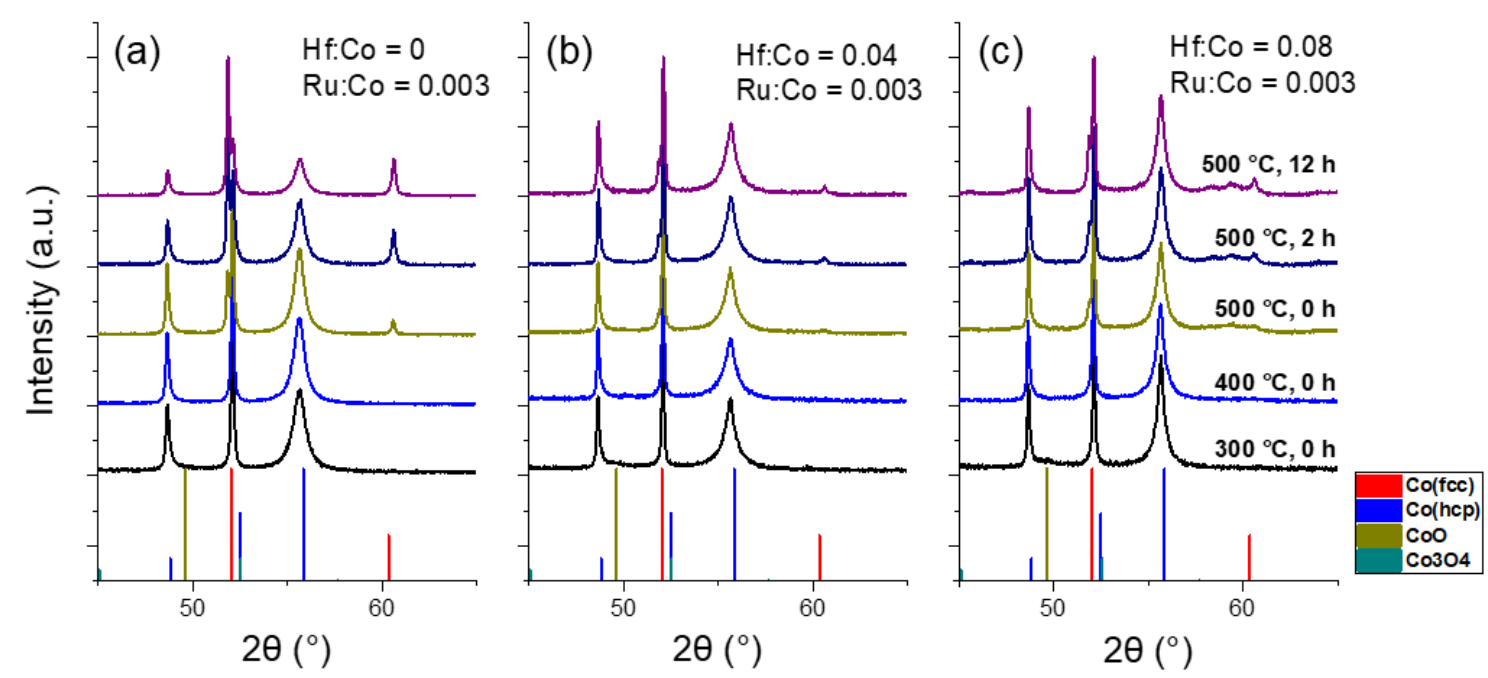

Figure 8 PXRD patterns of unsupported Co samples with $\mathrm{Ru}: \mathrm{Co}=0.003$ and with (a) $\mathrm{Hf}: \mathrm{Co}=0$, (b) Hf:Co $=$ 0.04 and (c) Hf:Co $=0.08$ and reduced at different temperatures and times.

\section{Conclusions}

Applying the described high throughput protocol we were able to screen different support materials and promotors for the Co based FTS catalysts. The protocol allowed us to identify SiC as a suitable support for active and stable catalyst materials. Furthermore the promotors $\mathrm{Ru}$ and $\mathrm{Hf}$ were identified, to not only increase the stability of the materials, but also to enhance the formation of the hcp Co phase, which is known to be more active in FTS than the fcc Co phase.

Samples containing $\mathrm{Co}, \mathrm{Ru}$ and $\mathrm{Hf}$ were scaled up alongside other samples promoted with $\mathrm{Ru}$ and rare earth elements and tested in the FTS under industrial conditions $\left(230^{\circ} \mathrm{C}, 20\right.$ bar $)$. Here the material with $\mathrm{Co}, \mathrm{Ru}$ and $\mathrm{Hf}$ showed higher $\mathrm{CO}$ conversion than the other materials tested and also showed the highest selectivity values towards $\mathrm{C}_{5+}$ components. The higher conversion and selectivity of this materials is attributed to the formation of the hep Co phase.

The further investigation of the effect of $\mathrm{Hf}$ in the formation of the different phases of Co shows that $\mathrm{Hf}$ shifts the reduction of $\mathrm{CoO}$ to higher temperatures and stabilizes the hcp phase at higher temperatures $\left(500{ }^{\circ} \mathrm{C}\right)$ also during longer reduction times. The addition of $\mathrm{Ru}$ to the samples facilitates the reduction of $\mathrm{CoO}$, such that all samples, even samples with higher amounts of $\mathrm{Hf}$ (up to 0.08 molar ratio) are reduced at temperatures of $300{ }^{\circ} \mathrm{C}$. The simultaneous addition of $\mathrm{Ru}$ and $\mathrm{Hf}$ to the samples inhibits the transformation of the hcp to the fcc phase, to a greater extent than achieved by the addition of Hf only.

\section{Acknowledgements}

This work was supported by the Engineering and Physical Sciences Research Council (EPSRC), UK (EP/N010531/1). We thank the Diamond Light Source for provision of beam time on the I11 beamline. M.J.R. thanks the Royal Society for the award of a Research Professorship. 


\section{References}

[1] J.-S. Jung, J.-S. Lee, G. Choi, S. Ramesh, D.J. Moon, The characterization of micro-structure of cobalt on $\gamma$ $\mathrm{Al}_{2} \mathrm{O}_{3}$ for FTS: Effects of pretreatment on $\mathrm{Ru}-\mathrm{Co} / \gamma-\mathrm{Al}_{2} \mathrm{O}_{3}$, Fuel, 149 (2015) 118-129.

[2] M.K. Gnanamani, G. Jacobs, W.D. Shafer, B.H. Davis, Fischer-Tropsch synthesis: Activity of metallic phases of cobalt supported on silica, Catalysis Today, 215 (2013) 13-17.

[3] A.Y. Khodakov, Fischer-Tropsch synthesis: Relations between structure of cobalt catalysts and their catalytic performance, Catalysis Today, 144 (2009) 251-257.

[4] M. Argyle, C. Bartholomew, Heterogeneous Catalyst Deactivation and Regeneration: A Review, Catalysts, 5 (2015) 145.

[5] P. Boldrin, J.R. Gallagher, G.B. Combes, D.I. Enache, D. James, P.R. Ellis, G. Kelly, J.B. Claridge, M.J. Rosseinsky, Proxy-based accelerated discovery of Fischer-Tropsch catalysts, Chemical Science, 6 (2015) 935944.

[6] J. Li, G. Jacobs, T. Das, B.H. Davis, Fischer-Tropsch synthesis: effect of water on the catalytic properties of a ruthenium promoted $\mathrm{Co} / \mathrm{TiO}_{2}$ catalyst, Applied Catalysis A: General, 233 (2002) 255-262.

[7] D.J. Moodley, J. van de Loosdrecht, A.M. Saib, M.J. Overett, A.K. Datye, J.W. Niemantsverdriet, Carbon deposition as a deactivation mechanism of cobalt-based Fischer-Tropsch synthesis catalysts under realistic conditions, Applied Catalysis A: General, 354 (2009) 102-110.

[8] L. Braconnier, E. Landrivon, I. Clémençon, C. Legens, F. Diehl, Y. Schuurman, How does activation affect the cobalt crystallographic structure? An in situ XRD and magnetic study, Catalysis Today, 215 (2013) 18-23. [9] J.-X. Liu, H.-Y. Su, D.-P. Sun, B.-Y. Zhang, W.-X. Li, Crystallographic Dependence of CO Activation on Cobalt Catalysts: HCP versus FCC, Journal of the American Chemical Society, 135 (2013) 16284-16287.

[10] S. Lyu, L. Wang, J. Zhang, C. Liu, J. Sun, B. Peng, Y. Wang, K.G. Rappé, Y. Zhang, J. Li, L. Nie, Role of Active Phase in Fischer-Tropsch Synthesis: Experimental Evidence of CO Activation over Single-Phase Cobalt Catalysts, ACS Catalysis, (2018) 7787-7798.

[11] E. Iglesia, Design, synthesis, and use of cobalt-based Fischer-Tropsch synthesis catalysts, Applied Catalysis A: General, 161 (1997) 59-78.

[12] P.J. vanBerge, R.C. Everson, Natural Gas Conversion IV, 107 (1997) 207-212.

[13] D.I. Enache, B. Rebours, M. Roy-Auberger, R. Revel, In Situ XRD Study of the Influence of Thermal Treatment on the Characteristics and the Catalytic Properties of Cobalt-Based Fischer-Tropsch Catalysts, Journal of Catalysis, 205 (2002) 346-353.

[14] Z. Pan, M. Parvari, D.B. Bukur, Fischer-Tropsch synthesis on Co/ZnO - Two step activation procedure for improved performance, Applied Catalysis A: General, 480 (2014) 79-85.

[15] X.Q. Zhao, S. Veintemillas-Verdaguer, O. Bomati-Miguel, M.P. Morales, H.B. Xu, Thermal history dependence of the crystal structure of Co fine particles, Physical Review B, 71 (2005) 024106.

[16] Y. Choong-Shik, S. Per, C. Hyunchae, The phase diagram of cobalt at high pressure and temperature: the stability of gamma(fcc)-cobalt and new epsilon'(dhcp) -cobalt, Journal of Physics: Condensed Matter, 10 (1998) L311.

[17] V.A. de la Peña O'Shea, P.R. de la Piscina, N. Homs, G. Aromí, J.L.G. Fierro, Development of Hexagonal Closed-Packed Cobalt Nanoparticles Stable at High Temperature, Chemistry of Materials, 21 (2009) 5637-5643.

[18] P. Serna, L.A. Baumes, M. Moliner, A. Corma, Combining high-throughput experimentation, advanced data modeling and fundamental knowledge to develop catalysts for the epoxidation of large olefins and fatty esters, Journal of Catalysis, 258 (2008) 25-34.

[19] U. Rodemerck, D. Wolf, O.V. Buyevskaya, P. Claus, S. Senkan, M. Baerns, High-throughput synthesis and screening of catalytic materials: Case study on the search for a low-temperature catalyst for the oxidation of lowconcentration propane, Chemical Engineering Journal, 82 (2001) 3-11.

[20] M. Lucas, P. Claus, High throughput screening in monolith reactors for total oxidation reactions, Applied Catalysis A: General, 254 (2003) 35-43.

[21] H.W. Turner, A.F. Volpe, W.H. Weinberg, High-throughput heterogeneous catalyst research, Surface Science, 603 (2009) 1763-1769.

[22] S. Lögdberg, D. Tristantini, Ø. Borg, L. Ilver, B. Gevert, S. Järås, E.A. Blekkan, A. Holmen, Hydrocarbon production via Fischer-Tropsch synthesis from $\mathrm{H} 2$-poor syngas over different $\mathrm{Fe}-\mathrm{Co} / \gamma-\mathrm{Al}_{2} \mathrm{O}_{3}$ bimetallic catalysts, Applied Catalysis B: Environmental, 89 (2009) 167-182.

[23] H. Karaca, O.V. Safonova, S. Chambrey, P. Fongarland, P. Roussel, A. Griboval-Constant, M. Lacroix, A.Y. Khodakov, Structure and catalytic performance of Pt-promoted alumina-supported cobalt catalysts under realistic conditions of Fischer-Tropsch synthesis, Journal of Catalysis, 277 (2011) 14-26.

[24] K. Shimura, T. Miyazawa, T. Hanaoka, S. Hirata, Fischer-Tropsch synthesis over alumina supported cobalt catalyst: Effect of promoter addition, Applied Catalysis A: General, 494 (2015) 1-11.

[25] G. Jacobs, P.M. Patterson, Y. Zhang, T. Das, J. Li, B.H. Davis, Fischer-Tropsch synthesis: deactivation of noble metal-promoted Co/ $\mathrm{Al}_{2} \mathrm{O}_{3}$ catalysts, Applied Catalysis A: General, 233 (2002) 215-226. 
[26] Ø. Borg, P.D.C. Dietzel, A.I. Spjelkavik, E.Z. Tveten, J.C. Walmsley, S. Diplas, S. Eri, A. Holmen, E. Rytter, Fischer-Tropsch synthesis: Cobalt particle size and support effects on intrinsic activity and product distribution, Journal of Catalysis, 259 (2008) 161-164.

[27] S. Karimi, A. Tavasoli, Y. Mortazavi, A. Karimi, Cobalt supported on Graphene - A promising novel Fischer-Tropsch synthesis catalyst, Applied Catalysis A: General, 499 (2015) 188-196.

[28] G. Jacobs, T.K. Das, Y. Zhang, J. Li, G. Racoillet, B.H. Davis, Fischer-Tropsch synthesis: support, loading, and promoter effects on the reducibility of cobalt catalysts, Applied Catalysis A: General, 233 (2002) 263-281.

[29] Z. Cai, J. Li, K. Liew, J. Hu, Effect of $\mathrm{La}_{2} \mathrm{O}_{3}$-dopping on the $\mathrm{Al}_{2} \mathrm{O}_{3}$ supported cobalt catalyst for FischerTropsch synthesis, Journal of Molecular Catalysis A: Chemical, 330 (2010) 10-17.

[30] S.A. Chernyak, E.V. Suslova, A.V. Egorov, L. Lu, S.V. Savilov, V.V. Lunin, New hybrid CNT-alumina supports for Co-based Fischer-Tropsch catalysts, Fuel Processing Technology, 140 (2015) 267-275.

[31] T.O. Eschemann, J. Oenema, K.P. de Jong, Effects of noble metal promotion for $\mathrm{Co} / \mathrm{TiO}_{2}$ Fischer-Tropsch catalysts, Catalysis Today, 261 (2016) 60-66.

[32] H. Wu, Y. Yang, H. Suo, M. Qing, L. Yan, B. Wu, J. Xu, H. Xiang, Y. Li, Effects of $\mathrm{ZrO}_{2}$ promoter on physic-chemical properties and activity of $\mathrm{Co} / \mathrm{TiO}_{2}-\mathrm{SiO}_{2}$ Fischer-Tropsch catalysts, Journal of Molecular Catalysis A: Chemical, 396 (2015) 108-119.

[33] S.L. Soled, E. Iglesia, R.A. Fiato, J.E. Baumgartner, H. Vroman, S. Miseo, Control of Metal Dispersion and Structure by Changes in the Solid-State Chemistry of Supported Cobalt Fischer-Tropsch Catalysts, Topics in Catalysis, 26 (2003) 101-109.

[34] C.H. Mauldin, S.M. Davis, K.B. Arcuri, Cobalt catalysts for the conversion of methanol and for FischerTropsch synthesis to produce hydrocarbons, in, Google Patents, 1987.

[35] T.E. Feltes, L. Espinosa-Alonso, E.d. Smit, L. D’Souza, R.J. Meyer, B.M. Weckhuysen, J.R. Regalbuto, Selective adsorption of manganese onto cobalt for optimized $\mathrm{Mn} / \mathrm{Co} / \mathrm{TiO}_{2}$ Fischer-Tropsch catalysts, Journal of Catalysis, 270 (2010) 95-102.

[36] J.A. Delgado, C. Claver, S. Castillón, D. Curulla-Ferré, V.V. Ordomsky, C. Godard, Fischer-Tropsch synthesis catalysed by small $\mathrm{TiO}_{2}$ supported cobalt nanoparticles prepared by sodium borohydride reduction, Applied Catalysis A: General, 513 (2016) 39-46.

[37] Y. Zhang, K. Liew, J. Li, X. Zhan, Fischer-Tropsch Synthesis on Lanthanum Promoted $\mathrm{Co} / \mathrm{TiO}_{2} \mathrm{Catalysts,}$ Catalysis Letters, 139 (2010) 1-6.

[38] A. Juan, D.E. Damiani, Characterization of RuMo-SiO2 catalysts. A comparative study before and after CO hydrogenation reaction, Journal of Materials Chemistry, 6 (1996) 1433-1439.

[39] D. Kistamurthy, A.M. Saib, D.J. Moodley, J.W. Niemantsverdriet, C.J. Weststrate, Ostwald ripening on a planar $\mathrm{Co} / \mathrm{SiO}_{2}$ catalyst exposed to model Fischer-Tropsch synthesis conditions, Journal of Catalysis, 328 (2015) 123-129.

[40] T. Riedel, M. Claeys, H. Schulz, G. Schaub, S.-S. Nam, K.-W. Jun, M.-J. Choi, G. Kishan, K.-W. Lee, Comparative study of Fischer-Tropsch synthesis with $\mathrm{H}_{2} / \mathrm{CO}$ and $\mathrm{H}_{2} / \mathrm{CO}_{2}$ syngas using $\mathrm{Fe}$ - and Co-based catalysts, Applied Catalysis A: General, 186 (1999) 201-213.

[41] A.Y. Khodakov, R. Bechara, A. Griboval-Constant, Fischer-Tropsch synthesis over silica supported cobalt catalysts: mesoporous structure versus cobalt surface density, Applied Catalysis A: General, 254 (2003) 273288.

[42] G.J. Haddad, B. Chen, J.J.G. Goodwin, Effect of $\mathrm{La}^{3+} \mathrm{Promotion}$ of $\mathrm{Co} / \mathrm{SiO}_{2}$ on $\mathrm{CO}$ Hydrogenation, Journal of Catalysis, 161 (1996) 274-281.

[43] A.Y. Khodakov, J. Lynch, D. Bazin, B. Rebours, N. Zanier, B. Moisson, P. Chaumette, Reducibility of Cobalt Species in Silica-Supported Fischer-Tropsch Catalysts, Journal of Catalysis, 168 (1997) 16-25.

[44] A. Michiaki, Y. Kiyotaka, H.Y. Zhuo, F. Kaoru, Fischer-Tropsch Synthesis with Supported Cobalt Catalyst. Promoting Effects of Lanthanum Oxide for Cobalt/Silica Catalyst, Bulletin of the Chemical Society of Japan, 69 (1996) 1509-1516.

[45] M.K. Gnanamani, G. Jacobs, U.M. Graham, M.C. Ribeiro, F.B. Noronha, W.D. Shafer, B.H. Davis, Influence of carbide formation on oxygenates selectivity during Fischer-Tropsch synthesis over Ce-containing Co catalysts, Catalysis Today, 261 (2016) 40-47.

[46] G. Jiao, Y. Ding, H. Zhu, X. Li, J. Li, R. Lin, W. Dong, L. Gong, Y. Pei, Y. Lu, Effect of $\mathrm{La}_{2} \mathrm{O}_{3}$ doping on syntheses of $\mathrm{C} 1-\mathrm{C} 18$ mixed linear $\alpha$-alcohols from syngas over the Co/AC catalysts, Applied Catalysis A: General, 364 (2009) 137-142.

[47] J.A. Díaz, A. Romero, A.M. García-Minguillán, A. Giroir-Fendler, J.L. Valverde, Carbon nanofibers and nanospheres-supported bimetallic (Co and Fe) catalysts for the Fischer-Tropsch synthesis, Fuel Processing Technology, 138 (2015) 455-462.

[48] M. Lacroix, L. Dreibine, B. de Tymowski, F. Vigneron, D. Edouard, D. Bégin, P. Nguyen, C. Pham, S. Savin-Poncet, F. Luck, M.-J. Ledoux, C. Pham-Huu, Silicon carbide foam composite containing cobalt as a highly selective and re-usable Fischer-Tropsch synthesis catalyst, Applied Catalysis A: General, 397 (2011) 6272. 
[49] I.G. Solomonik, K.O. Gryaznov, V.F. Skok, V.Z. Mordkovich, Formation of surface cobalt structures in SiC-supported Fischer-Tropsch catalysts, RSC Advances, 5 (2015) 78586-78597.

[50] G.R. Johnson, S. Werner, K.C. Bustillo, P. Ercius, C. Kisielowski, A.T. Bell, Investigations of element spatial correlation in Mn-promoted Co-based Fischer-Tropsch synthesis catalysts, Journal of Catalysis, 328 (2015) 111-122.

[51] M.J. Keyser, R.C. Everson, R.L. Espinoza, Fischer-Tropsch studies with cobalt-manganese oxide catalysts: Synthesis performance in a fixed bed reactor, Applied Catalysis A: General, 171 (1998) 99-107.

[52] S. Zeng, Y. Du, H. Su, Y. Zhang, Promotion effect of single or mixed rare earths on cobalt-based catalysts for Fischer-Tropsch synthesis, Catalysis Communications, 13 (2011) 6-9.

[53] D. Lorito, C. Ruocco, V. Palma, A. Giroir-Fendler, F.C. Meunier, Reconstruction of ceria-supported Pt-Co particles under $\mathrm{H}_{2}$ and $\mathrm{CO}$ at $220^{\circ} \mathrm{C}$, Applied Catalysis B: Environmental, 197 (2016) 56-61.

[54] W. Ma, G. Jacobs, T.K. Das, C.M. Masuku, J. Kang, V.R.R. Pendyala, B.H. Davis, J.L.S. Klettlinger, C.H. Yen, Fischer-Tropsch Synthesis: Kinetics and Water Effect on Methane Formation over $25 \% \mathrm{Co} / \gamma-\mathrm{Al}_{2} \mathrm{O}_{3}$

Catalyst, Industrial \& Engineering Chemistry Research, 53 (2014) 2157-2166. 